09,04

\title{
Релаксация колебательно-возбужденных состояний в твердых бинарных системах карбонат-сульфат
}

\author{
(C) А.Р. Алиев ${ }^{1}$, И.Р. Ахмедов ${ }^{1,2}$, М.Г. Какагасанов ${ }^{1,2}$, З.А. Алиев ${ }^{1}$, \\ М.М. Гафуров ${ }^{1,2}$, К.Ш. Рабаданов ${ }^{2}$, А.М. Амиров ${ }^{2}$ \\ ${ }^{1}$ Институт фризики им. Х.И. Амирханова ДагНЦ РАН, \\ Махачкала, Россия \\ ${ }^{2}$ Аналитический центр коллективного пользования ДагНЦ РАН, \\ Махачкала, Россия \\ E-mail: amilaliev@rambler.ru
}

(Поступила в Редакцию 10 мая 2017 г.)

Методами спектроскопии комбинационного рассеяния изучены процессы молекулярной релаксации в твердых бинарных системах карбонат-сульфат $\mathrm{Li}_{2} \mathrm{CO}_{3}-\mathrm{Li}_{2} \mathrm{SO}_{4}, \mathrm{Na}_{2} \mathrm{CO}_{3}-\mathrm{Na}_{2} \mathrm{SO}_{4}, \mathrm{~K}_{2} \mathrm{CO}_{3}-\mathrm{K}_{2} \mathrm{SO}_{4}$. Обнаружено, что время релаксации колебания $v_{1}(\mathrm{~A})$ аниона $\mathrm{CO}_{3}^{2-}$ в бинарной системе меньше, чем в индивидуальном карбонате. Показано, что увеличение скорости релаксации объясняется наличием в системе дополнительного механизма релаксации колебательно-возбужденных состояний карбонат-иона. Этот механизм связан с возбуждением колебания другого аниона $\left(\mathrm{SO}_{4}^{2-}\right)$ и „рождением“ решеточного фонона. Установлено, что условием реализации такого релаксационного механизма является то, что разность частот указанных колебаний должна соответствовать области достаточно высокой плотности состояний фононного спектра.

Авторы благодарят за поддержку РФФИ (проект № 17-02-00920_а).

DOI: 10.21883/FTT.2018.02.45390.140

\section{1. Введение}

Исследование процессов молекулярной релаксации методами колебательной спектроскопии дает богатую информацию о структурно-динамических свойствах конденсированной системы [1]. Такого рода исследования основаны на том факте, что ширины полос в колебательном спектре обратно пропорциональны временам молекулярной релаксации [2]. При этом каждый из релаксационных процессов дает вклад в общую ширину колебательной полосы. Молекулярная релаксация может быть разделена на ориентационную [3] и колебательную [4]

$$
\delta=\delta_{V}+\delta_{R},
$$

где $\delta$ - ширина колебательной линии; $\delta_{V}, \delta_{R}-$ вклады в ширину за счет процессов колебательной и ориентационной релаксации. Процессы колебательной релаксации, в свою очередь, подразделяются на адиабатические и неадиабатические [5]

$$
\delta_{V}=\delta_{\mathrm{ad}}+\delta_{\text {nad }},
$$

где $\delta_{\text {ad }}, \delta_{\text {nad }}-$ вклады в ширину за счет адиабатических и неадиабатических процессов колебательной релаксации. Среди адиабатических наибольшее значение имеют процессы колебательной дефазировки [6]. К неадиабатическим процессам относится релаксация за счет отталкивательных [7], диполь-дипольных [8] и ион-дипольных [9] взаимодействий, а также резонансный обмен колебательными квантами [8] и внутримолекулярный распад колебательных состояний с участием фононов [10]. В последнем случае внутримолекулярная колебательная релаксация рассматриваемой моды сопровождается рождением колебания с меньшей частотой и некоторым возмущением ближайшего окружения.

Учитывая все это, ширину колебательной полосы можно представить в виде суммы соответствующих вкладов [11-14]

$$
\delta=\delta_{\text {dep }}+\delta_{\text {dd }}+\delta_{\text {id }}+\delta_{\text {rep }}+\delta_{\text {res }}+\delta_{\text {imp }}+\delta_{R} .
$$

Здесь $\delta_{\mathrm{dep}}$ - вклад в ширину спектральной линии за счет колебательной дефазировки; $\delta_{\mathrm{dd}}, \delta_{\mathrm{id}}, \delta_{\text {rep }}$ - вклады за счет диполь-дипольных, ион-дипольных, отталкивательных взаимодействий; $\delta_{\text {res }}$ - вклад за счет резонансной передачи колебательных квантов; $\delta_{\text {imp }}$ - вклад за счет процессов внутримолекулярного фононного распада колебательно-возбужденных состояний.

Целью настоящей работы является анализ и сравнение процессов молекулярной релаксации в индивидуальных кристаллах и бинарных твердых системах, а также выявление возможных дополнительных механизмов релаксации колебательно-возбужденных состояний молекулярных ионов в бинарных твердых системах по сравнению с индивидуальными кристаллами. В работе [14] нами были исследованы твердые бинарные системы нитрат-перхлорат. Настоящая работа является продолжением исследования твердых бинарных систем.

\section{2. Объекты исследования}

В качестве объектов исследования выбраны кристаллические: карбонат лития $\mathrm{Li}_{2} \mathrm{CO}_{3}$, сульфат лития $\mathrm{Li}_{2} \mathrm{SO}_{4}$, карбонат натрия $\mathrm{Na}_{2} \mathrm{CO}_{3}$, сульфат натрия 


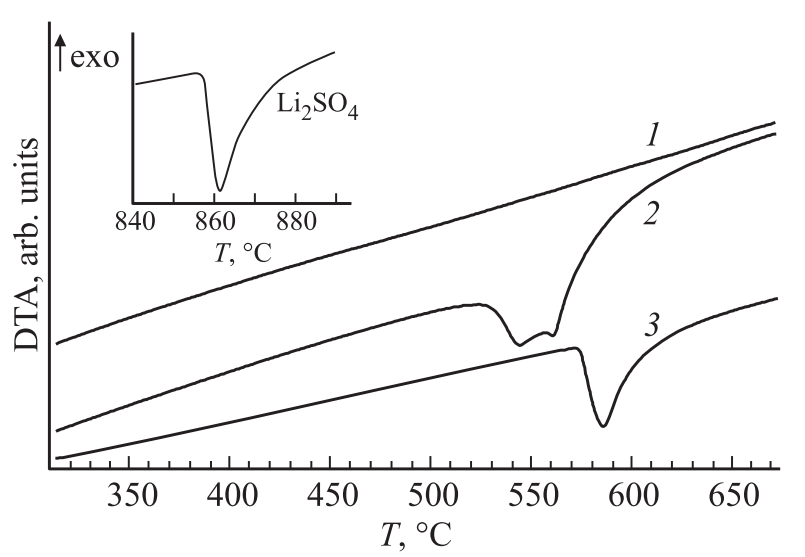

Рис. 1. Кривые ДТА $\mathrm{Li}_{2} \mathrm{CO}_{3}(1), 0.5 \mathrm{Li}_{2} \mathrm{SO}_{4}-0.5 \mathrm{Li}_{2} \mathrm{CO}_{3}$ (2), $\mathrm{Li}_{2} \mathrm{SO}_{4}$ (3) (см. текст).

$\mathrm{Na}_{2} \mathrm{SO}_{4}$, карбонат калия $\mathrm{K}_{2} \mathrm{CO}_{3}$, сульфат калия $\mathrm{K}_{2} \mathrm{SO}_{4}$, a также эквимолярные бинарные твердые системы: карбонат лития-сульфат лития $\mathrm{Li}_{2} \mathrm{CO}_{3}-\mathrm{Li}_{2} \mathrm{SO}_{4}$, карбонат натрия-сульфат натрия $\mathrm{Na}_{2} \mathrm{CO}_{3}-\mathrm{Na}_{2} \mathrm{SO}_{4}$ и карбонат калия-сульфат калия $\mathrm{K}_{2} \mathrm{CO}_{3}-\mathrm{K}_{2} \mathrm{SO}_{4}$.

Эквимолярные системы карбонат-сульфат приготавливались смешиванием предварительно прогретых при температуре $150^{\circ} \mathrm{C}$ мелкодисперсных порошков карбоната и сульфата. При этом использовались реактивы марки ХЧ или ЧДА. Полученная смесь медленно нагревалась до температуры, при которой гарантированно расплавятся оба компонента. Затем полученная бинарная система медленно охлаждается и кристаллизуется. В такой системе концентрации анионов $\mathrm{CO}_{3}^{2-}$ и $\mathrm{SO}_{4}^{2-}$ совпадают. При этом происходит образование твердых растворов замещения и равномерное распределение анионов по кристаллической решетке [14]. Синтез проводился в атмосфере сухого аргона в Аналитическом центре коллективного пользования Дагестанского научного центра РАН (АЦКП ДагНЦ РАН).

Карбонат лития $\mathrm{Li}_{2} \mathrm{CO}_{3}$ представляет собой бесцветный кристалл с моноклинной решеткой пространственной группы $C 2 / c$, температура плавления равна $T_{m}=720-732^{\circ} \mathrm{C}$ [15-17]. По некоторым данным [16] при $T_{s}=410^{\circ} \mathrm{C}$ в $\mathrm{Li}_{2} \mathrm{CO}_{3}$ происходит структурный переход, однако мы его не наблюдали (рис. 1).

Сульфат лития $\mathrm{Li}_{2} \mathrm{SO}_{4}$ представляет собой бесцветный кристалл с моноклинной решеткой пространственной группы $P 2_{1} / c$. Переход в кубическую форму пространственной группы $I 43 m$ происходит при температуре $T_{s}=575-586^{\circ} \mathrm{C}$, температура плавления равна $T_{m}=858-860^{\circ} \mathrm{C}$ [15-17]. По нашим данным $T_{s}=574^{\circ} \mathrm{C}$, $T_{m}=857^{\circ} \mathrm{C}$ (рис. 1$)$.

Бинарная система $\mathrm{Li}_{2} \mathrm{CO}_{3}-\mathrm{Li}_{2} \mathrm{SO}_{4}$ имеет температуру плавления $T_{m}=551-553^{\circ} \mathrm{C}[16,17]$, по нашим данным $T_{m}=550^{\circ} \mathrm{C}$ (рис. 1$)$.

Карбонат натрия $\mathrm{Na}_{2} \mathrm{CO}_{3}$ представляет собой бесцветный кристалл. При температурах ниже $350^{\circ} \mathrm{C}[15,17]$ существует $\alpha$-модификация с моноклинной решеткой пространственной группы $C 2$ или $C m$. В интервале температур $359-479^{\circ} \mathrm{C}$ существует $\beta$-модификация с моноклинной кристаллической решеткой, а выше $485^{\circ} \mathrm{C}-$ гексагональная $\gamma$-модификация пространственной группы $P 6_{3} m c \quad[15,17,18]$. Температура плавления равна $T_{m}=850-858^{\circ} \mathrm{C}[15-18]$, по нашим данным $T_{m}=852^{\circ} \mathrm{C}$ (рис. 2).

Сульфат натрия $\mathrm{Na}_{2} \mathrm{SO}_{4}$ представляет собой бесцветный кристалл, известный в четырех полиморфных модификациях. При температурах ниже $185^{\circ} \mathrm{C}$ имеет место ромбическая $\alpha$-модификация пространственной группы $F_{d d d}$. В интервале температур $185-241^{\circ} \mathrm{C}$ существует ромбическая $\beta$-модификация. При температуpax $241-597^{\circ} \mathrm{C}$ устойчива гексагональная $\gamma$-модификация пространственной группы $P 6_{3} m c$. При температуpax выше $597^{\circ} \mathrm{C}$ имеет место ромбическая модификация [15]. По данным [16,17] структурный фазовый переход происходит при $T_{s}=247-249^{\circ} \mathrm{C}$, по нашим данным $T_{s}=251^{\circ} \mathrm{C}$ (рис. 2). Температура плавления $T_{m}=884^{\circ} \mathrm{C} \quad[15-18]$, по нашим данным $T_{m}=884^{\circ} \mathrm{C}$ (рис. 2).

Бинарная система $\mathrm{Na}_{2} \mathrm{CO}_{3}-\mathrm{Na}_{2} \mathrm{SO}_{4}$ имеет температуру плавления $T_{m}=827-830^{\circ} \mathrm{C}[16-18]$, по нашим данным $T_{s}=321^{\circ} \mathrm{C}$ и $T_{m}=800^{\circ} \mathrm{C}$ (рис. 2).

Карбонат калия $\mathrm{K}_{2} \mathrm{CO}_{3}$ - это бесцветный кристалл моноклинной сингонии пространственной группы $P 2_{1} / c$.

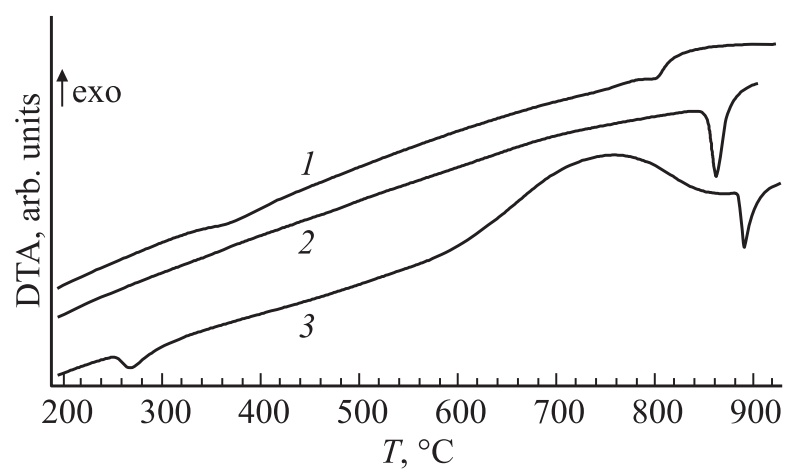

Рис. 2. Кривые ДТА $0.5 \mathrm{Na}_{2} \mathrm{SO}_{4}-0.5 \mathrm{Na}_{2} \mathrm{CO}_{3}$ (1), $\mathrm{Na}_{2} \mathrm{CO}_{3}$ (2), $\mathrm{Na}_{2} \mathrm{SO}_{4}$ (3).

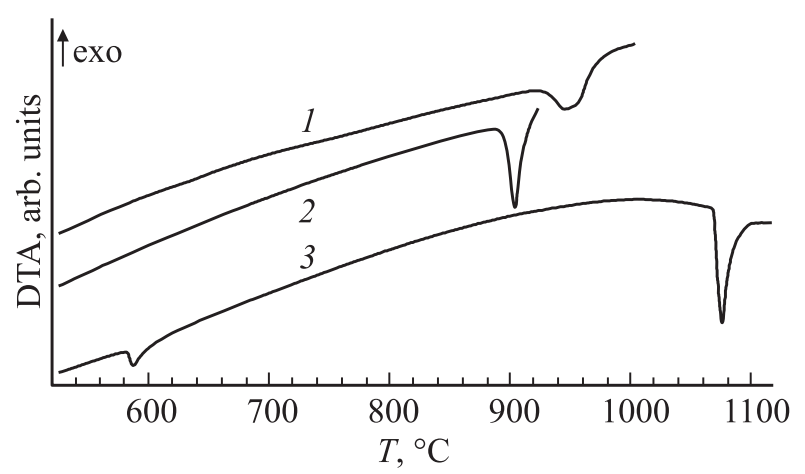

Рис. 3. Кривые ДТА $0.5 \mathrm{~K}_{2} \mathrm{SO}_{4}-0.5 \mathrm{~K}_{2} \mathrm{CO}_{3}$ (1), $\mathrm{K}_{2} \mathrm{CO}_{3}$ (2), $\mathrm{K}_{2} \mathrm{SO}_{4}(3)$. 
Переход в гексагональную модификацию происходит при температуре $T_{s}=420-422^{\circ} \mathrm{C}[15,17]$. Температура плавления $T_{m}=891-905^{\circ} \mathrm{C}$ [15-18], по нашим данным $T_{m}=891^{\circ} \mathrm{C}$ (рис. 3 ).

Сульфат калия $\mathrm{K}_{2} \mathrm{SO}_{4}-$ бесцветный кристалл ромбической сингонии пространственной группы Pnam. Переход в гексагональную модификацию пространственной группы $P 6_{3} / m m c$ происходит при $T_{s}=$ $=583-584^{\circ} \mathrm{C}[15-17]$, по нашим данным $T_{s}=581^{\circ} \mathrm{C}$ (рис. 3). Температура плавления равна $T_{m}=$ $=1069-1074^{\circ} \mathrm{C}[15-18]$, по нашим данным $T_{m}=1070^{\circ} \mathrm{C}$ (рис. 3).

Бинарная система $\mathrm{K}_{2} \mathrm{CO}_{3}-\mathrm{K}_{2} \mathrm{SO}_{4}$ имеет температуру плавления $T_{m}=930-940^{\circ} \mathrm{C}[16-18]$, по нашим данным $T_{m}=920^{\circ} \mathrm{C}$ (рис. 3 ).

\section{3. Эксперимент}

Дифференциальный термический анализ (DTA) проводился на приборе синхронного термического анализа STA 449 F3 Jupiter (NETZSCH) при скорости нагрева $20 \mathrm{~K} / \mathrm{min}$ в атмосфере аргона в алундовых тиглях (рис. 1-3) в АЦКП ДагНЦ РАН. Обработка данных и интегрирование пиков проводились с помощью встроенных прикладных программ фирмы NETZSCH.

Для получения информации о динамических межионных взаимодействиях нами использован анализ формы контуров колебаний молекулярных анионов в спектрах комбинационного рассеяния (КР) твердой системы. Непосредственно из фононного спектра получить подобную информацию не представляется возможным. Спектр малых частот высокотемпературных фаз ионных кристаллов, как правило, регистрируется в виде широкой бесструктурной полосы, обусловленной термическим смешением различных типов (трансляционных, либрационных) внешних колебаний структурных единиц.

Концентрационные изменения состава твердой системы также слабо проявляются в спектрах малых частот ионных кристаллов и расплавов, содержащих молекулярные ионы [19]. В то же время, изменения структуры и динамики твердой системы оказывает влияние на колебательные состояния ее структурных единиц и отражается в спектрах инфракрасного поглощения и КР. Поэтому использование колебательных спектров, соответствующих внутренним модам молекулярных ионов, для получения информации о процессах молекулярной релаксации в ионных кристаллах и расплавах представляется вполне обоснованным.

Спектры КР возбуждались излучением аргонового лазера ЛГ-106м-1 с длиной волны $\lambda=488 \mathrm{~nm}$ и регистрировались спектрометром ДФС-52М от 900 до $1170 \mathrm{~cm}^{-1}$ в области полносимметричных колебаний $v_{1}(\mathrm{~A})$ карбонат-иона $v_{1}\left(\mathrm{CO}_{3}^{2-}\right) \approx 1040-1080 \mathrm{~cm}^{-1}$ и сульфат-иона $v_{1}\left(\mathrm{SO}_{4}^{2-}\right) \approx 970-1005 \mathrm{~cm}^{-1}$ в температурном интервале $20-640^{\circ} \mathrm{C}$. Ширины входной и выходной щелей монохроматора устанавливались одинаковыми и в зависимости от интенсивности рассеяния выбирались от 100 до $200 \mu \mathrm{m}$. Положения максимумов колебательных полос фиксировалось с точностью $\pm 0.5 \mathrm{~cm}^{-1}$, а их ширины с точностью $\pm 0.1 \mathrm{~cm}^{-1}$. Температура образцов поддерживалась в процессе регистрации спектров с точностью $\pm 0.5 \mathrm{~K}$. Методика регистрации и обработки спектров КР подробно описана в [11-14].

На рис. 4 показаны спектры КР твердых систем $\mathrm{Li}_{2} \mathrm{CO}_{3}-\mathrm{Li}_{2} \mathrm{SO}_{4}, \mathrm{Na}_{2} \mathrm{CO}_{3}-\mathrm{Na}_{2} \mathrm{SO}_{4}, \mathrm{~K}_{2} \mathrm{CO}_{3}-\mathrm{K}_{2} \mathrm{SO}_{4}$ в области колебаний $v_{1}$ анионов $\mathrm{CO}_{3}^{2-}$ и $\mathrm{SO}_{4}^{2-}$. Контуры рассматриваемых колебаний резко поляризованы (изотропное рассеяние) и потому их формирование всецело можно приписать процессам колебательной релаксации.

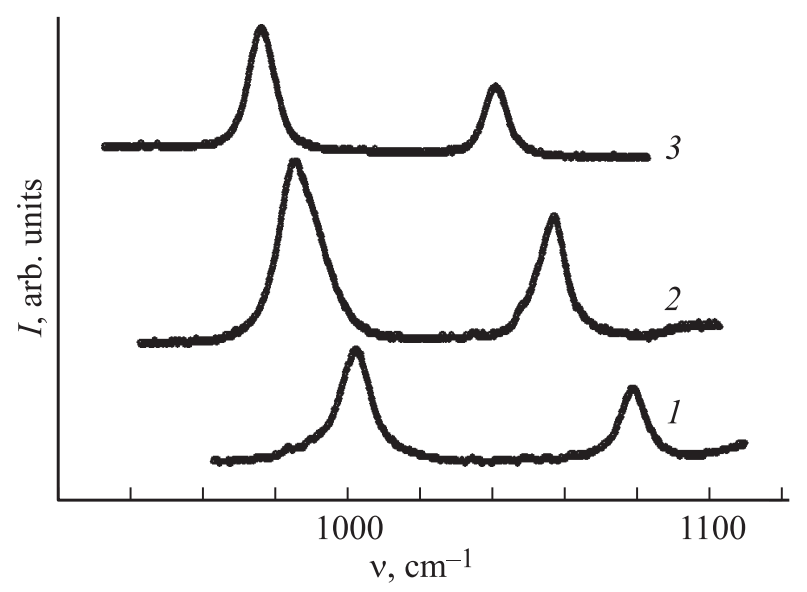

Рис. 4. Спектры КР твердых бинарных систем карбонат лития-сульфат лития $\mathrm{Li}_{2} \mathrm{CO}_{3}-\mathrm{Li}_{2} \mathrm{SO}_{4}(1)$, карбонат натриясульфат натрия $\mathrm{Na}_{2} \mathrm{CO}_{3}-\mathrm{Na}_{2} \mathrm{SO}_{4}(2)$ и карбонат калия-сульфат калия $\mathrm{K}_{2} \mathrm{CO}_{3}-\mathrm{K}_{2} \mathrm{SO}_{4}$ (3) в области валентных полносимметричных колебаний $v_{1}(\mathrm{~A})$ карбонат-иона $\mathrm{CO}_{3}^{2-}$ и сульфат-иона $\mathrm{SO}_{4}^{2-}$ при температуре $T=200^{\circ} \mathrm{C}$ при ширинах входной и выходной щелей монохроматора $150 \mu \mathrm{m}$.

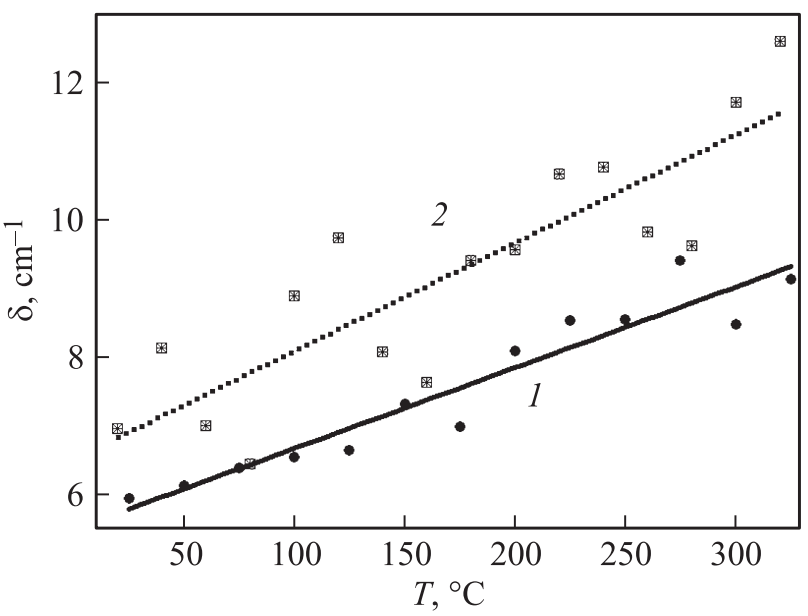

Рис. 5. Сравнение температурных зависимостей ширины спектральной линии КР в области валентного полносимметричного колебания $v_{1}(\mathrm{~A})$ карбонат-иона $\mathrm{CO}_{3}^{2-}$ в карбонате лития $\mathrm{Li}_{2} \mathrm{CO}_{3}(1)$ и в системе карбонат лития-сульфат лития $\mathrm{Li}_{2} \mathrm{CO}_{3}-\mathrm{Li}_{2} \mathrm{SO}_{4}(2)$. 


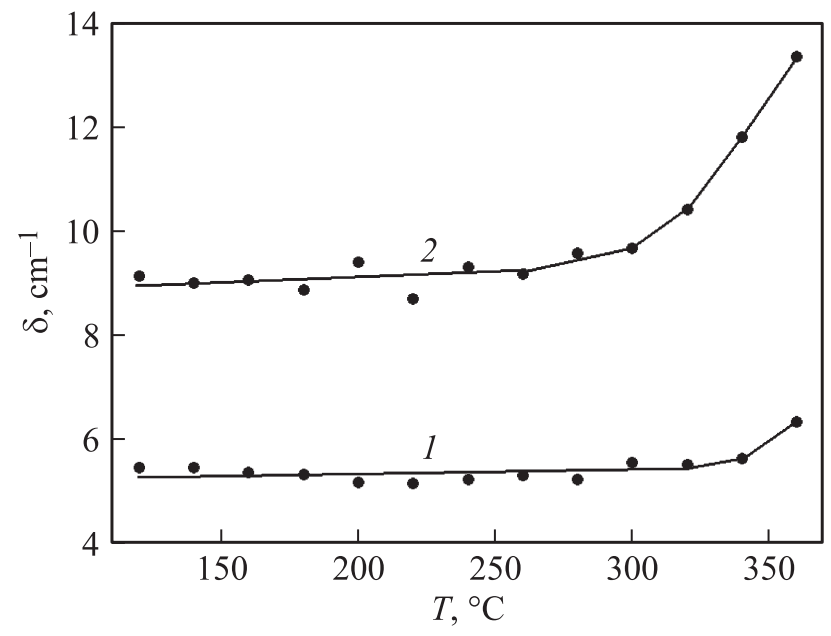

Pис. 6. Сравнение температурных зависимостей ширины спектральной линии КР в области валентного полносимметричного колебания $v_{1}(\mathrm{~A})$ карбонат-иона $\mathrm{CO}_{3}^{2-}$ в карбонате натрия $\mathrm{Na}_{2} \mathrm{CO}_{3}$ (1) и в системе карбонат натрия-сульфат натрия $\mathrm{Na}_{2} \mathrm{CO}_{3}-\mathrm{Na}_{2} \mathrm{SO}_{4}(2)$.

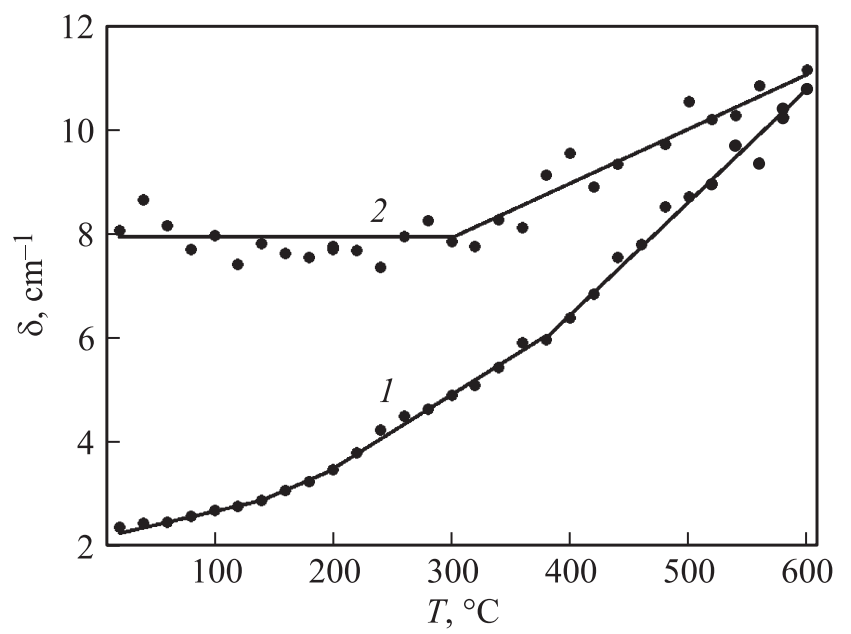

Рис. 7. Сравнение температурных зависимостей ширины спектральной линии КР в области валентного полносимметричного колебания $v_{1}(\mathrm{~A})$ карбонат-иона $\mathrm{CO}_{3}^{2-}$ в карбонате калия $\mathrm{K}_{2} \mathrm{CO}_{3}(1)$ и в системе карбонат калия-сульфат калия $\mathrm{K}_{2} \mathrm{CO}_{3}-\mathrm{K}_{2} \mathrm{SO}_{4}(2)$.

На рис. 5-7 представлены температурные зависимости ширин $\delta$ контура $v_{1}(\mathrm{~A})$ колебания $\mathrm{CO}_{3}^{2-}$ в кристаллах $\mathrm{Li}_{2} \mathrm{CO}_{3}(1), \mathrm{Na}_{2} \mathrm{CO}_{3}(1)$ и $\mathrm{K}_{2} \mathrm{CO}_{3}(1)$ и в бинарных системах $\mathrm{Li}_{2} \mathrm{CO}_{3}-\mathrm{Li}_{2} \mathrm{SO}_{4}$ (2), $\mathrm{Na}_{2} \mathrm{CO}_{3}-\mathrm{Na}_{2} \mathrm{SO}_{4}$ (2) и $\mathrm{K}_{2} \mathrm{CO}_{3}-\mathrm{K}_{2} \mathrm{SO}_{4}$ (2) соответственно. Сравнение ширин $\delta$ контура $v_{1}(\mathrm{~A})$ колебания $\mathrm{CO}_{3}^{2-}$ в бинарных системах с соответствующими данными для кристаллов $\mathrm{Li}_{2} \mathrm{CO}_{3}$, $\mathrm{Na}_{2} \mathrm{CO}_{3}$ и $\mathrm{K}_{2} \mathrm{CO}_{3}$ показывает, что величины $\delta$ и скорость температурного уширения значительно выше в спектре КР бинарных систем $\mathrm{Li}_{2} \mathrm{CO}_{3}-\mathrm{Li}_{2} \mathrm{SO}_{4}, \mathrm{Na}_{2} \mathrm{CO}_{3}-\mathrm{Na}_{2} \mathrm{SO}_{4}$ и $\mathrm{K}_{2} \mathrm{CO}_{3}-\mathrm{K}_{2} \mathrm{SO}_{4}$ соответственно.

\section{4. Обсуждение}

Все перечисленные выше факторы молекулярной релаксации, имеющие место в индивидуальных кристаллах, актуальны и для бинарных твердых систем [11-14]. Надо иметь в виду, что в бинарной твердой системе структура исходных кристаллов меняется, и это может сказаться на изменении характеристик соответствующих спектральных переходов. Однако в бинарных твердых системах, имеющих два сорта молекулярных ионов, возможен еще один релаксационный механизм, если различные молекулярные ионы имеют близкие по частотам внутримолекулярные колебания (ВМК). При этом релаксация колебания $v_{i}$ молекулярного иона одного сорта может сопровождаться возбуждением соответствующего $v_{j}$ колебания молекулярного иона другого сорта, а разница энергий передаваться фононам решетки. Такой неупругий межмолекулярный обмен колебательными квантами реализуется при условиях [14]

$$
\begin{gathered}
v_{i}>v_{j}, \\
v_{i}-v_{j}<v_{m}=k_{\mathrm{B}} T_{\mathrm{D}}(h c)^{-1}=T_{\mathrm{D}} 0.6938 \mathrm{~cm}^{-1} \mathrm{~K}^{-1},
\end{gathered}
$$

где $v_{m}$ - максимальная частота фононного спектра в $\mathrm{cm}^{-1}, T_{\mathrm{D}}$ - температура Дебая в К. Если $T_{\mathrm{D}}=200 \mathrm{~K}$, то $v_{m}=139 \mathrm{~cm}^{-1}$. Обычно для ионных и молекулярных кристаллов $T_{\mathrm{D}}>200 \mathrm{~K}$ и соответственно $v_{m}>139 \mathrm{~cm}^{-1}$. Поэтому несложно подобрать бинарную твердую систему, для которой выполняются условия (4).

Тогда ширину колебательной полосы бинарной твердой системы можно представить в виде

$$
\delta=\delta_{\text {dep }}+\delta_{\text {dd }}+\delta_{\text {id }}+\delta_{\text {rep }}+\delta_{\text {res }}+\delta_{\text {imp }}+\delta_{\text {emp }}+\delta_{R},
$$

$\delta_{\text {emp }}$ - вклад в ширину спектральной линии за счет процессов релаксации колебательно-возбужденных состояний, связанных с неупругим межмолекулярным обменом колебательными квантами.

В бинарных твердых системах карбонат-сульфат условие (4) выполняется, если в качестве колебания $v_{i}$ выбрать колебание $v_{1}\left(\mathrm{CO}_{3}^{2-}\right) \approx 1040-1080 \mathrm{~cm}^{-1}$, а в качестве колебания $v_{j}$ выбрать колебание $v_{1}\left(\mathrm{SO}_{4}^{2-}\right) \approx$ $\approx 970-1005 \mathrm{~cm}^{-1}$ [20-22]. Разность частот этих колебаний составляет $v_{i}-v_{j} \approx 35-110 \mathrm{~cm}^{-1}$.

Температуры Дебая в ряду сульфатов $\mathrm{Li}_{2} \mathrm{SO}_{4}, \mathrm{Na}_{2} \mathrm{SO}_{4}$, $\mathrm{K}_{2} \mathrm{SO}_{4}$ убывают как 705, 521, $481 \mathrm{~K}$ [23]. Температуры Дебая карбонатов $\mathrm{Li}_{2} \mathrm{CO}_{3}, \mathrm{Na}_{2} \mathrm{CO}_{3}, \mathrm{~K}_{2} \mathrm{CO}_{3}-$ это величины того же порядка. Поэтому мы можем считать, что в бинарных твердых системах карбонатсульфат $T_{\mathrm{D}}>300 \mathrm{~K}$ и соответственно $v_{m}>208 \mathrm{~cm}^{-1}$. При этом разность $v_{i}-v_{j}$ частот колебаний карбонатиона и сульфат-иона будет меньше, чем максимальная частота $v_{m}$ фононного спектра системы и условие (4) окажется выполненным. Следовательно, возможна диссипация колебательной энергии ВМК карбонат-иона с последующим возбуждением соответствующего ВМК сульфат-иона и рождением решеточного фонона, так как 
разница в частотах указанных ВМК попадает в область достаточно высокой плотности состояний фононного спектра исследуемых кристаллов $[24,25]$.

\section{5. Заключение}

Установлено, что имеют место факторы, способствующие увеличению скорости релаксации внутримолекулярных колебательных мод в бинарных твердых системах по сравнению с индивидуальными кристаллами. По нашему мнению, объяснение данному экспериментальному факту можно найти, если допустить наличие дополнительного механизма релаксации колебательновозбужденных состояний в бинарных твердых системах. При реализации этого механизма возможен обмен колебательными квантами между различными молекулами или молекулярными ионами с близкими значениями частот внутримолекулярных колебаний. Такой неупругий межмолекулярный обмен должен сопровождаться „рождением“ решеточного фонона, который забирает разницу между энергиями релаксирующего и возбуждаемого колебаний. Предлагаемый механизм релаксации актуален, когда разность частот этих колебаний меньше, чем максимальная частота фононного спектра системы.

Выводы настоящей работы хорошо согласуются с выводами нашей статьи [14], где сообщалось о результатах исследования твердых бинарных систем нитратперхлорат.

\section{Список литературы}

[1] Ю.К. Воронько, А.А. Соболь, В.Е. Шукшин. ФТТ 49, 1871 (2007).

[2] А.В. Раков. Тр. ФИАН СССР 27, 111 (1964).

[3] К.А. Валиев, Е.Н. Иванов. УФН 109, 31 (1973).

[4] В.Е. Погорелов, А.И. Лизенгевич, И.И. Кондиленко, Г.П. Буян. УФН 127, 683 (1979).

[5] С.А. Кириллов. В сб.: Динамические свойства молекул и конденсированных систем / Под ред. А.Н. Лазарева. Наука, Л. (1988). С. 190.

[6] D.W. Oxtoby. J. Chem. Phys. 70, 2605 (1978).

[7] К.А. Валиев. ЖЭТФ 40, 1832 (1961).

[8] К.А. Валиев. Оптика и спектроскопия 11, 465 (1961).

[9] К. Сарка, С.А. Кириллов. Укр. физ. журн. 26, 1118 (1981).

[10] М.А. Иванов, Л.Б. Квашина, М.А. Кривоглаз. ФТТ 7, 2047 (1965).

[11] М.М. Гафуров, А.Р. Алиев. Расплавы 2, 41 (2000).

[12] А.Р. Алиев, М.М. Гафуров. Журн. физ. химии 75, 477 (2001).

[13] A.R. Aliev, M.M. Gafurov, I.R. Akhmedov. Chem. Phys. Lett. 359, 262 (2002).

[14] А.Р. Алиев, И.Р. Ахмедов, М.Г. Какагасанов, 3.А. Алиев, М.М. Гафуров, К.Ш. Рабаданов, А.М. Амиров. ФТТ 59, 736 (2017).

[15] Химическая энциклопедия. Сов. энциклопедия, М.: Т. 2 (1990). C. 288-289, 607-608; T. 3 (1992). C. 182-183, 185.

[16] C.W. Bale, A.D. Pelton. CALPHAD 6, 255 (1982).
[17] Y. Dessureault, J. Sangster, A.D. Pelton. J. Electrochem. Soc. 137, 2941 (1990).

[18] D. Lindberg, R. Backman, P. Chartrand. J. Chem. Thermodynamics 39, 942 (2007).

[19] M.H. Brooker, G.N. Papatheodorou. In: Adv. Molten Salt Chem. Volume 5 / Ed. G. Mamantov. Elsevier, Amsterdam (1983). V. 5. P. 26.

[20] К. Кольрауш. Спектры комбинационного рассеяния. ИЛ, М. (1952). $466 \mathrm{c}$.

[21] Л.М. Свердлов, М.А. Ковнер, Е.П. Крайнов. Колебательные спектры многоатомных молекул. Наука, М. (1970). $559 \mathrm{c}$.

[22] The Aldrich Library of Infrared Spectra 2nd ed. / Ed. C.J. Pouchert. Aldrich Chemical Company Inc. (1978).

[23] О.В. Головко. Электронная структура, химическая связь и физико-химические свойства сульфатов щелочных металлов. Автореф. канд. дис. Кемеровский гос. ун-т, Кемерово (2009). $22 \mathrm{c}$.

[24] D.W. James, W.H. Leong. J. Chem. Phys. 49, 5089 (1968).

[25] W.H. Leong, D.W. James. Austral. J. Chem. 22, 499 (1969). 